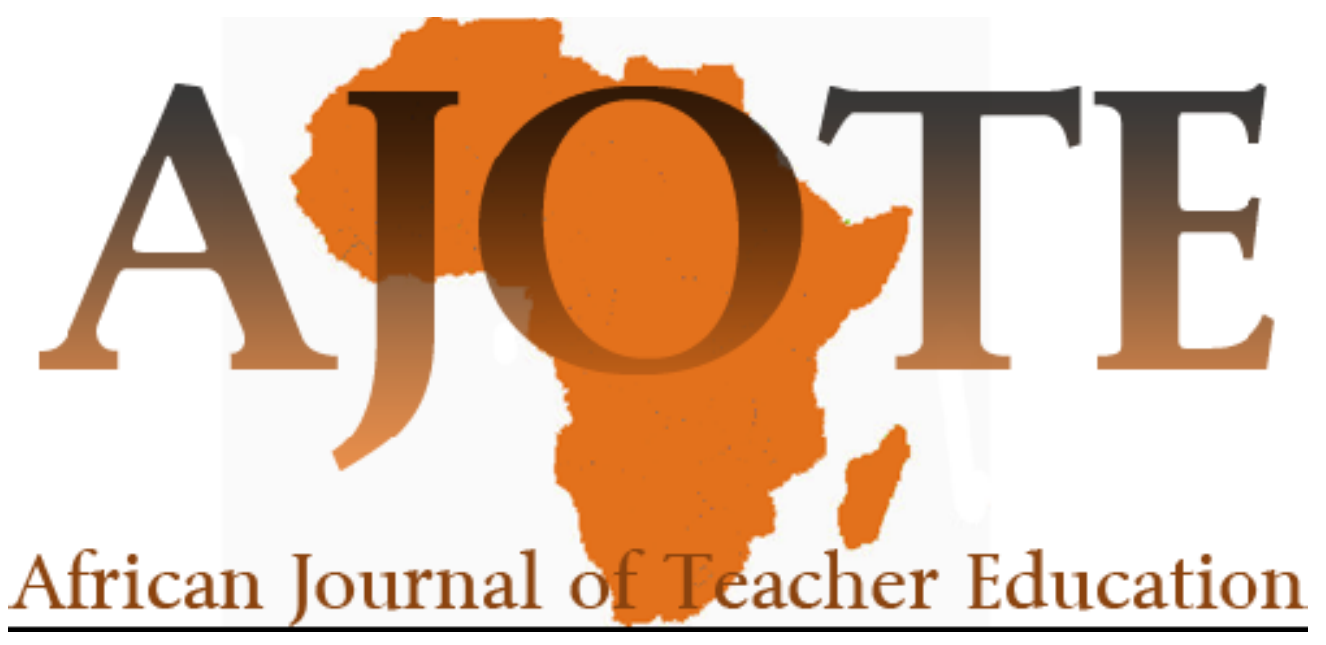

\title{
EDUCATING MARGINALIZED GIRLS: EXAMINING THE CONCEPT OF TUSEME
}

\author{
Kennedy Ongaga \\ University of North Carolina, USA \\ Mary Ombonga \\ University of North Carolina, USA
}

\begin{abstract}
This article examines the concept of Tuseme, a Swahili word, meaning "Let's Speak Out" and how it is used to empower girls in a Center of Excellence in Kenya. The Center serves as a school and home to girls rescued from female genital mutilation and child marriages. Data were collected from students, teachers and the Center's principal. Findings indicated that Tuseme, through its creative activities, empowers students with life skills, including how to speak out, build self-confidence, decision making, negotiation and leadership skills. It also helps teachers to acquire and use gender-responsive instructional strategies, which boost girls' academic success, self-efficacy and a consciousness to identify, understand, and articulate problems that affect them and take action to solve them.

Keywords: Tuseme, Women Education, Empowerment, Cultural Marginalization, Female Genital Mutilation, Gender Equality, Kenya Education
\end{abstract}




\section{Introduction}

Under the framework of Education for All, adopted in 2000 at the World Education Forum in Dakar, many governments in sub-Saharan Africa made tremendous progress to ensure that children, especially girls of school-going-age, have access to free basic education. In recent years, the push for girls' education has shifted from focusing on access to improving the quality of their educational experience by focusing on school contexts (Anderson \& Hodgkin, 2009; Tembon \& Fort, 2008). This progress notwithstanding, there still exists significant underlying socio-cultural challenges in rural and marginalized areas that continue to impede girls' participation in education (FAWE, 2001; Mlama, 2005 \& UNICEF, 2003). ${ }^{1}$ Some of the challenges that endured the test of global efforts and investment of colossal resources are manifested in female genital mutilation (FGM), child marriages, poverty, and HIV \& AIDS.

To address these challenges, most governments developed policy instruments and initiated interventions to mobilize, advocate, and build capacity to promote education for all children. Recent research on education for girls in sub-Saharan Africa (e.g., Kirk, 2008; Chege \& Sifuna, 2006; Ongaga \& Ombonga, 2009) reveal that when girls are empowered and given opportunities to speak up for themselves, they develop resilient characteristics which provide them with the capacity to adapt to challenging and threatening circumstances in their communities. This article examines the concept of Tuseme (Let's Speak Out) and how it is used in a Center of Excellence to empower and give voice to girls who are either rescued or escape from retrogressive cultural practices including, female genital mutilation and child marriages.

\section{Purpose}

This article is part of a larger qualitative case study we conducted in one of the two Girls Centers of Excellence in Kenya, established by the Forum for African Women Educationalists' (FAWE). The purpose of the study was to understand experiences of girls who are rescued from female genital mutilation or early marriages and brought to the Center. For purposes of this article, we examine the meaning and manifestations of Tuseme and how it is used as a strategy to empower girls at the Center of Excellence.

A Center of Excellence refers to an educational intervention school established by FAWE that uses a gender responsive approach to offer quality education by paying attention to the physical, academic, and social-cultural dimensions of both girls and boys (FAWE, 2005). This educational intervention "consists of a package of strategies that effectively address barriers to girls' education in the academic, social, and physical school environments and surrounding community" (Tembon \& Fort, 2008, p. 259).

\section{Theoretical Framework}

In order to discuss the concept of Tuseme and how it gives girls a voice to understand, interrogate, and confront marginalizing practices, beliefs and attitudes that make them vulnerable to adversity, we briefly review a Gender Responsive Model (GRM) on which frames this article. Developed by FAWE, GRM advocates for a rights-based approach, which considers gender equality to be a function of the "right to education" (access and participation), "rights within education" (gender-sensitive environments, processes and outcomes) and "rights through

\footnotetext{
${ }^{1}$ FAWE is a pan-African non-governmental organization working in 32 countries in Sub-Saharan Africa to create conducive school environments for girls to access education of good quality.
}

AJOTE Vol. 2. No. 2 (2012) 
education" (the links between quality education and wider gender justice in society) (FAWE, 2006b). To achieve this goal, this model provides for the integration of a holistic and participatory approach to teaching and learning in which children are active participants in observing, exploring, listening, reasoning, questioning and 'coming to know' (Diaw, 2008; Mlama, 2005; UNICEF, 2009). Proponents of GRM further champion the transformation of school environments to become gender responsive in order to meet the social, academic and developmental needs of both boys and girls (FAWE, 2000).

Enshrined in the GRM is a gender responsive pedagogy (GRP), which is used to train and equip teachers to teach the whole child. Teachers are required to develop intellectual, social, emotional, and pedagogical learning by using gender referents to impart knowledge, skills, and attitudes that are encapsulated in the ethics of care (Noddings, 2002a). Caring in the context of GRP is rooted on close, reciprocal relationships between the students and teachers, among students, and the personalization of the school environment. It is characterized by patience, persistence, facilitation, validation, and empowerment for the participants. It is also manifested in the form of "teacher attitudes, expectations, and behaviors about students' human value, intellectual capability, and performance responsibilities. Teachers demonstrate caring for children as students and as people" (Thomspon \& Ongaga, 2010, p.45). Commitment to these professional dispositions, personal and professional qualities, and building an inclusive, participatory, and respective school culture has the potential to transform schools and school grounds to be physically and psychologically safe for girls. It provides adequate facilities for personal hygiene, and policies to fight discrimination, harassment and abuse. In this context, both girls and boys have opportunities to understand, challenge and influence forces that contribute to their marginalization, while reclaiming their power to be heard as experts on their own lives. The curriculum, using the words of Dewey (1902), must be "psychologized" if students are to be relevant, interested, and effective in their learning.

The ultimate goal of the GRM is to empower girls and boys to acquire skills to know, to be, to do and to live together (Clift \& Jensen, 2005; UNICEF, 2009). As used in this study, empowerment denotes "the process through which marginalized people, such as the poor, minorities, girls and women, become aware of their subordination and acquire the necessary knowledge and skills to overcome their marginalization. In other words, empowerment is about giving voice to the voiceless and strength to the powerless" (FAWE, 2005, p. 3). In the following section, we provide the background of Tuseme.

\section{Background of Tuseme}

Tuseme, a Swahili word meaning "Let's Speak Out," is a process meant to train girls to express their views openly on matters that affect their personal, academic, and social development, and to learn to actively take part in finding solutions to those matters (FAWE, 2005). Tuseme utilizes a human rights-based approach to promote inclusive and persuasive gender responsive discourse in girls' education. According to Mlama (2005), Tuseme is "designed to enable girls to understand the gender construct of the society they live in, to identify and analyze the emergent problems and how they hinder their academic and social development, to speak out about the problems, and take action to solve them" (p. 2).

The concept of Tuseme emerged from the works of Mlama (1983) and Leshoai (1978) in which they posit the use of art, specifically theatre art, as a tool for shaping consciousness and galvanizing people into action. In 1996 the Department of Fine and Performing Arts at the

AJOTE Vol. 2. No. 2 (2012) 
University of Dar es Salaam (USDM) in Tanzania used Mlama and Leshoai's concepts to develop theater-based empowerment strategies that give marginalized students a platform to identify and analyze problems that impede their academic and social development. FAWE adopted the use of Tuseme philosophy in Centers of Excellence as a way for girls to identify factors that lead to their social and academic marginalization and to be actively involved in finding solutions. In this context, Tuseme was meant to address the following factors, which impede girls' participation in school:

1. School drop out

2. Poor academic achievement

3. School girl pregnancy

4. Sexual harassment

5. Any other gender related problems as identified by the girls themselves.

In this article, we explored the meaning and manifestations of Tuseme in a Center of Excellence in Kenya. We used the following three questions to guide this study.

1. How is Tuseme enacted in the Center of Excellence?

2. What impact does it have on students and teachers?

3. What implications does Tuseme have in the school community?

\section{Methods and Data Sources}

This article is based on a larger qualitative study that utilized a case study approach to explore and understand the experiences of girls in a Center of Excellence in Kenya. As a well established method of inquiry in qualitative research, case study tends to be particularly responsive to research questions of "why" and "how" (Winegardner, 1999). According to Stake (1995) and Feagin (1991), case studies must have boundaries and always strive towards providing a holistic understanding of culture. Given the issues that necessitated the establishment of the Center of Excellence, the case study approach provided us with a flexible yet integrated framework for which we holistically examined the participants' experiences in their natural context. Such flexibility, argues Winegardener (1999), lies in the customization of the case to address a wide range of research questions and types of cases that incorporate a variety of data collection, analysis, reporting techniques, epistemological orientations, and disciplinary perspectives, all of which provide their own standards of scholarship.

We used purposeful sampling to select seven participants from the Center of Excellence in Kenya. The logic and power of purposeful sampling (Patton, 2002) "lies in selecting information-rich cases for study in depth. Information-rich cases are those from which one can learn a great deal about issues of central importance to the purpose of the research" (p. 169). We kept the sample size small in order to provide a richer narrative data for analysis (Denzin \& Lincoln, 2000). Student participants included four girls aged between 14 and 18 years. The girls were either rescued or had run away from their families to the Center to avoid female genital mutilation and being given away for marriage. They were either in standard seven or eight and had stayed in the Rescue Center ${ }^{2}$ for at least three years, a period we considered long enough for them to understand and articulate their experiences, programs and activities related to Tuseme. We also interviewed the Center's head teacher and two teachers, one female and one male. The

\footnotetext{
${ }^{2}$ A special dormitory in the Center of Excellence that serves as a home for rescued or run away girls.
}

AJOTE Vol. 2. No. 2 (2012) 
female teacher comes from the community in which the Center is located. As a 10-year old girl, she was rescued from being given away after undergoing female genital mutilation and now she is in the mission of rescuing and empowering girls who are going through the same experience. The male participant was one of the two male teachers in the Center. Like the head teacher, he belonged to an ethnic community that does not believe in nor practices female genital mutilation or child marriages.

Data for this study were collected for a period of two months using unstructured face-toface open-ended interviews (Kvale, 1996), observations (Creswell, 1998) and document analysis (Patton, 2002; Glesne \& Peshkin, 1992). Some of the documents we analyzed included those leading to the establishment of the Center, minutes of the Board of Governors, workshops, staff meetings, brochures, newsletters, and commitments from reconciliation workshops.

The head teacher and teacher participants were interviewed individually while three of the four student participants were put in a focus group. One student participant self-selected to be interviewed individually. Focus group discussion and interviews each lasted for about 60 minutes and with prior participant permission, we tape recorded them and later transcribed them verbatim for analysis.

Data analysis began at the time of data collection and continued to the coding, classifying, and categorizing phases (Patton, 2002; Huberman \& Miles, 1994). We categorized data based on the participants' responses to the guiding questions. This is in line with Lincoln and Guba's (1985) contention that data analysis must begin at the very first phase of data collection because continuing analysis can facilitate "emergent design, grounding of theory and emergent structure of later data collection phases" (p. 242).

Given that qualitative research can be intrusive in its method of inquiry, and the fact that we were seeking to understand personal lived experiences, we made an attempt to minimize any ethical challenges by explicitly explaining the objectives of our study to all participants. As the guardian of the students, the head teacher provided us with a written permission to seek students' assent to participate in the study. We explained to the students that their participation in the study was voluntary and that they could withdraw at any time of the study without penalty. We clearly communicated to the students the nature and purpose of our study and made it a process of unfolding rather than a once-and-for-all declaration. With background knowledge of the students' community's cultural beliefs and practices, we tried to ask culturally relevant questions in a relevant manner. To protect the participant's identity, we have used pseudo names in data analysis and reporting findings. The study was also approved by institutional Human Research Protection program.

\section{Findings}

Findings reveal that Tuseme is used in the Center as an intensive formal process used to equip girls with knowledge, attitudes, abilities, and life-skills that empower them to take charge of their lives. The ultimate goal of this process is to lead girls to diagnose, articulate, and take action on social injustices that marginalize and impede their physical, social and academic development. We capture the findings in four intertwined layers (see Figure 1).

AJOTE Vol. 2. No. 2 (2012) 


\section{Figure 1: Tuseme Process}

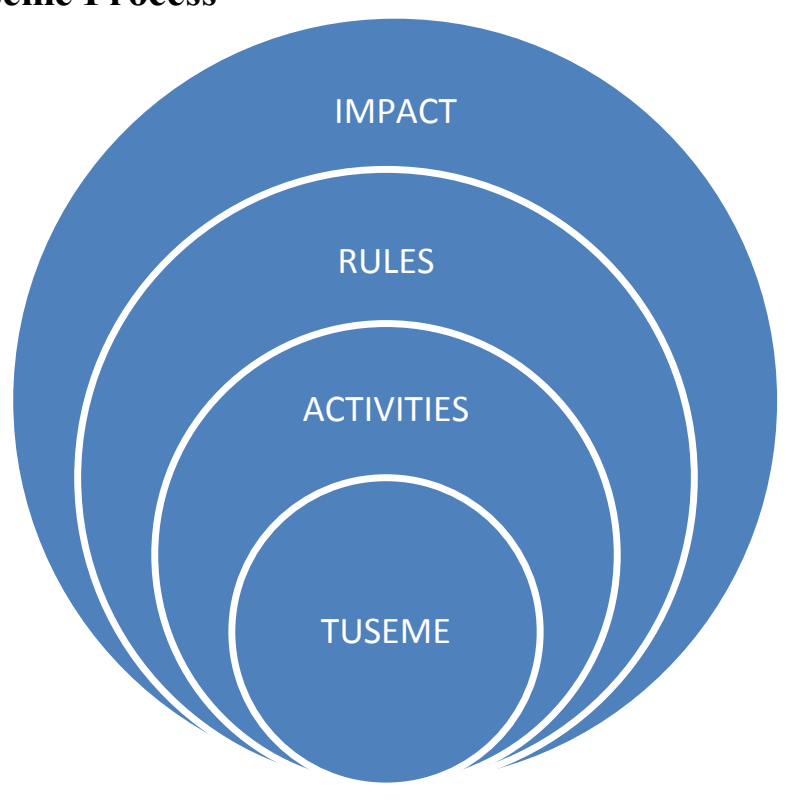

\section{Tuseme - Stages and Activities}

Tuseme process assumes that when girls are empowered to speak up for themselves, they can also overcome gender-based constraints, especially those sanctioned by their communities' cultural beliefs and practices such as FGM and early marriages. We garnered that the philosophy of Tuseme is manifested in various programs and activities including; clubs, festivals, reconciliation workshops, skits, newsletter, role models, and sharing of experiences. All girls, especially those rescued from female genital mutilation and early marriages, undergo a systematic step-by-step orientation geared towards giving them a chance to understand, investigate, reflect, and take action on problems that hinder their academic and social development. The stages and activities are facilitated by teachers and student leaders who are already trained and equipped with Tuseme skills (See Table 1).

\section{Table 1: Tuseme Stages and Activities}

\begin{tabular}{ll}
\multicolumn{1}{c}{ Stages } & \multicolumn{1}{c}{ Activities } \\
\hline Preliminary & School and community sensitization on girls education \\
Familiarization & $\begin{array}{l}\text { Students understand the Center's history, location, environment, } \\
\text { demographic data, teaching and learning facilities (library, } \\
\text { classroom, laboratories, toilets), and other social amenities. }\end{array}$ \\
& Gathering information on issues in and out of school related to the \\
Data Collection & Exademic and social development of both boys and girls. \\
& understanding of the issues and problems, their root causes, effects \\
Data Analysis & and possible solutions. \\
& Translation of the issues and suggested solutions into a theatre \\
Theatre Creation & performance. The stage involves some basic training in production \\
& issues.
\end{tabular}

AJOTE Vol. 2. No. 2 (2012) 


\section{Kennedy Ongaga and Mary Ombonga}

Theatre performance

Post-performance discussion

Action Planning

Training in life skills for action

Creation of Tuseme Clubs

Taking Action

Monitoring and evaluation
Platform for communicating the issues to other members of the community to provoke their involvement in the discussion and persuade them to take action and support girls' education.

Held immediately after the performance to discuss the issues highlighted in the performance. The audience is encouraged to discuss the issues, find solutions and propose strategies for action. A tool to guide the implementation of actions suggested to solve identified problems.

Students acquire a set of skills to empower them to deal with genderbased constraints to their education and self-development. The training includes building self-confidence and esteem, speaking out, decision making, assertiveness, negotiation skills, leadership and self- control.

Student-centered structures to facilitate the implementation of activities towards the empowerment of girls, including those in action plan. They also serve as speaking out platforms for students to discuss issues related to their social and academic welfare. The clubs are considered pillars of the existence and development of TUSEME activities in the school.

Students are trained in different strategies they can adopt to solve the problems. The student are equipped with skills for engaging and convincing school administration, teachers, other students and community members to take action to improve the social and academic situation at schools.

Tracking progress of empowerment of girls: Speaking out, selfconfidence, negotiation and other personal development skills; implementing Tuseme action plan. Also, assessing gender responsiveness of the overall school environment (socially, physically, and academically). Documenting the outcomes and activities through reports and other forms such as video, photographs and posters.

\section{Tuseme Rules}

Tuseme ground rules (see Table 2) are meant to inject a democratic process that ensures all students, regardless of their age or any other variable, have an equal chance to understand forces that marginalize them, share and speak out about their experiences and find ways to be part of the solution. The rules are designed to guide the girls beyond the Center, especially when they transition to secondary schools, most of which are boarding and co-educational.

\section{Table 2: Tuseme Ground Rules}

○ TUSEME is participatory, everyone should be involved.

- Democratic principles should be observed in all processes, such as choosing leaders and assigning tasks. Everybody has some role to play. 
- Gender should be taken into account, including observing gender equality in participation, both in terms of numbers, ages and levels of participation.

- Everybody's views and opinions must be respected.

$\circ$ Ethics and etiquette should be observed.

- Punctuality and discipline should be maintained.

- When creating groups, the teacher should mix students across lines of gender (in case of co-ed school), age, social class, academic ability, religion, ethnicity and any other variable.

- For each day of the workshop, new leaders should be elected to allow broad participation. The leaders include:

- 2 chairpersons for the day (in case of a co-ed school, gender should be taken into account- 1 girl and 1 boy).

- 2 recorders for the day (in case of a co-ed school, gender should be taken into account- 1 girl and 1 boy).

- 2 timekeepers for the day (in case of a co-ed school, gender should be taken into account- 1 girl and 1 boy).

\section{Role of Teachers in Tuseme}

Teachers are an integral part in the success of Tuseme program and activities. Because they oversee the academic performance of students and spearhead the empowerment process, they are given in-service training to acquire professional skills to help them understand the empowering process. We garnered that all teachers are required to undergo a Gender Responsive in-service training to acquire knowledge and instructional skills that help them to integrate gender responsive teaching in their classrooms. The training equips them with skills to create a dialogical and trusting climate in the classroom and school, which affirms and respects all students. They are encouraged to embrace participatory teaching methods, whose central tenets include, collaboration, participatory, discussion, reflection, and co-operative ways that make students active learners. By so doing, they awaken and nurture girls' abilities and give them voices to grow in confidence. The head teacher stated that:

Because we receive and deal with girls who come to the Center with multiple needs, all of us, teachers and school staff get continuous training on how to be gender responsive and meet their learning needs. Teachers are trained to improve and make their instructional strategies participatory. Sometimes they have to challenge their own beliefs (Mavoka, personal interview, July 30, 2007). A teacher participant echoed the head teacher's views stating, "the training process takes us through ways that make us to stop thinking like ordinary teachers." A review of training materials for teachers in the Center revealed some curriculum and pedagogical areas for inservice training for teachers (see Table 3).

\section{Table 3: Gender Responsive Training for Teachers}

Gender responsive:

- Teaching and learning materials

- Lesson plans

- Language in classroom

AJOTE Vol. 2. No. 2 (2012) 
- Classroom interaction

- Management of sexual maturation

- Classroom set-up

- Strategies to eliminate sexual harassment

- School management systems

- Monitoring and evaluation

\section{Impact of Tuseme}

The Center of Excellence serves as a safe haven for girls from different backgrounds, including those rescued from pre-arranged marriages and female genital mutilation. The head teacher described them below:

We have girls here who have been married a day, a week or a month. They stayed with her husband and carried out all the chores of a wife, they are brought here to be a student with other students, most of them children. We also have young mothers; not married but have got children of their own, they are here with us. We have some girls who were forced to undergo FGM against their wish and they were rescued or ran away to come here. We also have girls, who have been abused sexually, but those ones still do not want to talk, they are still trying to come to terms with the trauma. And then there are those who are abandoned here by their parents because of poverty. We are a boarding school, they bring them here in the pretext of looking for a place for them to study, but it is actually food. What do you do, do you turn them away? Another biggest problem that is emerging is that of HIV and AIDS. Currently, we have about 114 student orphans - they have lost either one or both parents. Some of the kids are HIV positive (Mavoka, personal interview, July 30, 2007).

The Center uses Tuseme activities to give girls a platform and a voice to reflect and talk about injustices against them. The head teacher described Tuseme as a living embodiment of a word that grew bigger than those who first uttered it. "Tuseme is a word that gets bigger and bigger, grows bigger than the person who first spoke it." In his view, "Tuseme helps girls see the connection between their past, the present, and hope for the future." Concurring with the head teachers' sentiments, the female teacher participant said, "Tuseme gives girls a second chance and power to challenge decisions that affect their own lives." The male teacher shared the same views saying, "many girls are now aware of their subordination as they are motivated to take steps to acquire the necessary knowledge and skills to overcome their marginalization." $\mathrm{He}$ continued:

Our girls have been sensitized through Tuseme that even those who are able to go home over the holidays and they know of other girls in their community who are threatened with forced marriages or FGM, they advise and encourage them to come here. Once they come here, they know they are safe and protected from any harm (Kavuli, personal interview, July 30, 2007).

We also sought to understand girls' views on how Tuseme was a voice of hope and transformation in their lives. We learned that their participation in Tuseme-related activities had raised their level of awareness on issues that affect them, need their attention, participation and action. Skits such as debates, drama, role plays, and mastering courage to share their past

AJOTE Vol. 2. No. 2 (2012) 
experiences had helped promote their public speaking skills, improved problem solving skills, and empowered them to challenge forces of their marginalization. They shared that through the use of theatre, they had researched issues that affect their academic performance. For instance, they conducted research on school dropouts, teenage pregnancy, and academic excellence. They presented their findings to the entire school community, including parents, local area chiefs, and visitors from the ministry of education.

These performances served as powerful avenues that mobilized and sensitized parents and the community and encouraged discussion of issues that are taboo in the community. For instance, girls in standards seven and eight had instigated the transfer of two male teachers who openly opposed the purpose of the Center and resented girls who ran away from their "husbands" or refused to undergo FGM. The head teacher confirmed the transfers stating:

It has not been easy, you find even some of our teachers who come from this community, support 'giving away' of these young girls. They stick to their culture because that is what they know, and what they believe in. If they were circumcised then why should someone tell them that their daughters shouldn't? Yes, we had to transfer some teacher. (Mavoka, personal interview, July 30, 2007).

While the transferred teachers' actions denote the undeniable force of culture, the students' voice and the principal's authority undergird the power of education. We attributed the action of girls to the knowledge and skills they had acquired through Tuseme.

Tuseme had also enabled them to know each other and their past experiences, most of which were similar. This helped them to support each other in academics through group discussions, debates, sharing learning materials, clothing and toiletries with newly-arrived girls. Together, they identified day-to-day problems both at home and in school, which constrains their access and performance in education.

With the help of teachers, we gathered that girls had started a youth magazine, Nisikie (hear me) in which they underscore their experiences and forces in the school and in the community that oppress, discriminate and put them in a servitude position. They use the magazine as an avenue to identify and share cultural structures, values, attitudes, and practices that contribute to their lack of self-confidence, assertiveness and self-esteem. A girl shared that "we try to ask the 'why, what, and how' questions and our goal is to sensitize other students, especially boys, our parents, and elders about us - girls, and the issues we go through."

Girls who live in the rescue center were using Tuseme workshops to speak to their parents. It is during this time that they voice their concerns, communicate typical cases of disempowerment, ask to be involved in matters that affect their lives, express their desire to reunite with their families, and demonstrate the value of education. We garnered that reconciling run-away girls and those rescued from FGM with their families was critical for their girls' survival and the Center's continuity. Teacher participants concurred that involving parents in their children's lives, and education in particular, is in line to changing their [parents'] attitudes and opinions regarding girls' education.

During reconciliation workshops, parents, area administration chiefs, district officers, Children's Rights officials, and the Center's staff attend, witness, and support those parents who commit to reconcile with their daughters. The head teacher shared about a reconciliation workshop he had previously facilitated:

AJOTE Vol. 2. No. 2 (2012) 
Whenever we call parents here, we have to call the children's officer to come and talk about the children's rights. They [parents] understand now that children have a right. Previously, the destiny of the children has always been in the hands of the father. He is the one to decides what should happen to you, who to go to school, whom to give away for marriage... Since the enactment of the Children's Rights Act, we are now telling them to give children their basic rights, including education, and you have to protect them. The chiefs have also now been sensitized. Whenever they have a baraza [community meeting], they talk about children's rights. There is a change of attitude taking root in this community (Mavoka, personal interview, June 24, 2007).

A review of documents on reconciliation workshops held in 2007 revealed that 49 girls, the largest number in a single year since the inception of the Center, were reconciled with their parents. This, according to the head teacher, confirmed the Centers' commitment and demonstrated parents' change of attitude to support their daughters' education. Also, local chiefs' declaration of their commitment (see Figure 2) to support girls' rights, education, and stop retrogressive practices such as FGM and child marriages in their areas of jurisdiction was paying off.

\section{Figure 2: Chiefs Commitment to Support Girls Rights and Education}

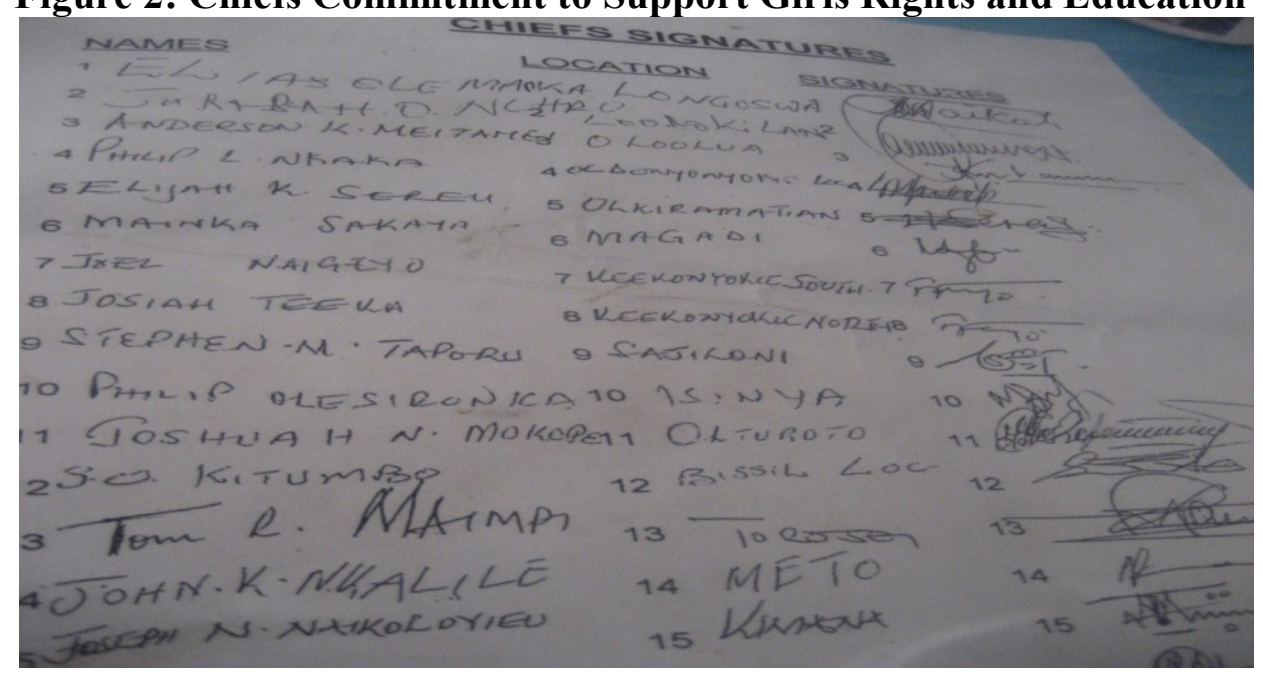

\section{Source: Girls Center of Excellence, Kajiado, Kenya}

Below, we present some of what we consider to be the most profound statements from the students that exemplify the impact of Tuseme activities on girls in the Center of Excellence:

We now know about the dangers of FGM, the teachers have told us and now we know we don't have to accept it. We have learned how to care for ourselves, cope with teenage challenges and how to avoid sexually transmitted diseases, like HIV, which we could have not known (Mukule, personal interview, June 24, 2007).

I know how to take care of myself. I can say everything, when you step on my rights. I don't keep quiet and it does not matter to me the level of your status in

AJOTE Vol. 2. No. 2 (2012) 
society, I will speak out. Tuseme has empowered me ... My self-esteem is high. I have also learnt to accept my strengths and weakness. (Mariam, focus group interview, June 24, 2007).

Tuseme has really opened me up. If I had not come here, many things could have happened to me. Maybe I could have been given away for marriage. Maybe I could have undergone that FGM. Here, I have learned how to speak up and fight for myself. Tuseme has taught me to be confident and believe in myself. (Naigeyo, focus group interview, June 30, 2007).

In our community, women and girls are there to be seen and not to be heard. Since I came here [Center] I have realized that it is unfair for our culture to put women down. I now have a voice, I can speak my mind when I see things that are not right. I can talk about my views without being intimidated by anybody. Tuseme has really helped me to realize my potential (Kaleje, personal interview, July 21, 2007).

We interpreted these vignettes to mean that Tuseme activities helped boost the girls' self-esteem, confidence, and assertiveness. It significantly enhanced their ability to analyze their community's values and practices while giving them a voice to speak up and negotiate to undergo alternative rites of passage to adulthood. They viewed education as one of the rites of passage. One girl said, "getting education is more important than the cows my father values so much. I am now married to education." She shared the big picture of how her life and that of other girls had changed since their coming to the Center and being involved in Tuseme activities. In this context, Tuseme programs and activities provided girls with a framework upon which they rediscover, redefine and re-write their individuality and future. With a mind to think, a voice to speak, and a chance to spur and influence action, Tuseme enabled them to express their views on problems that affect their academic and social development.

\section{Conclusion}

The liberating force of Tuseme starts by putting school experiences of girls in Africa into perspective. Rihani (2006) gives a vivid description of this experience and its inherent challenges.

Her first challenge is access to a safe school where she can focus on her schooling without threat of violence, harassment, physical labor, gender discrimination or personal hygiene concerns. Her second challenge is to find quality education that is purposeful, relevant, and meaningful so it will have value to the girl and her family as an end in itself. Finally, education becomes more challenging and the obstacles become greater...as they progress through the school system...family and societal pressure that may tell her that education is of little value for a girl ( $\mathrm{p}$. 66).

To understand these experiences, Tuseme captures the essence of empowering education, whose pedagogical goals, according to Shor (1992), are meant to "relate personal growth to public life, to develop strong skills, academic knowledge, habits of inquiry, and critical curiosity about society, power, inequality, and change...The learning process is negotiated, requiring leadership 


\section{Kennedy Ongaga and Mary Ombonga}

by the teacher, and mutual teacher-student authority" (pp. 15-16). We posit that gender responsive pedagogies, in which Tuseme is anchored, defy the conventions of traditional educational practices with respect to educating girls. The strategies inherent in this paradigm enable teachers to assume the role of cultural brokers (Gentemann \& Whitehead, 1983) in which they critically examine existing concomitant relationships between educational practices and cultural tenets that influence how teaching and learning is mediated. This program also offers them a chance to interrogate and transform their attitudes, expectations, and instructional strategies in a way that enhances students' academic competence, personal confidence, courage, and the will to act.

We are cognizant of the fact that teachers are taken through in-service training to acquire gender responsive skills, attitudes, and practices. However, we argue that at this level of their educational career, teachers are more likely to perpetuate the cultural fabric of the schooling process- structures, ethos, programs, and etiquette, which have always positioned girls as weak and incapable of attaining educational excellence. We posit that training of teachers and administrators on gender responsive practices, including personalized and caring relationships should begin at the pre-service education programs and continue to in-service professional development programs. This is likely to provide teachers with the urgency, moral imperative and professional responsibility to deconstruct and transform some longstanding pedagogical assumptions, societal beliefs, and practices about educating the girl-child.

We further argue that gender responsive pedagogies, specifically Tuseme practices should be mainstreamed into educational policies and institutional practices. These arenas perpetuate and re-create complex social, cultural, and educational environments that incite social imaginations. We suggest that further research be conducted on integrating best practices used in the Centers of Excellence in educational policies and practices as one way to identify and address gaps in policies, attitudes, practices and socio-cultural contexts that constrain or enhance girls' education. By so doing, education for girls, and indeed for all children, becomes transformative and empowering. In any case, children are our most valuable resource and investment for the future.

\section{REFERENCES}

Anderson, A., \& Hodgkin, M. (2009). "Education in crisis through to development: the gender Implications," The Inter-Agency Network for Education in Emergencies. Accessed from, http://www.ineesite.org/toolkit/INEEcms/uploads/1114/Education_in_Crisis_Gender_Implicatio $\underline{\text { ns.pdf }}$

Chege, F., \& Sifuna, D. (2006). Women and girls education in Kenya. UNESCO.

Clift, S., \& Jensen, B. (2005). The health promoting school: International advances in theory, evaluation and practice. Emdrupvej, Danish University of Education Press.

Colclough, C. (1994). Under-enrollment and low quality in African primary schooling: Towards a gender-sensitive solution. Nairobi: Forum for African Women Educationalists.

AJOTE Vol. 2. No. 2 (2012) 
Creswell, J. W. (1998). Qualitative Inquiry and research design: Choosing among five traditions. Thousand Oaks, Sage Publications.

Denzin, N. K., \& Lincoln, Y. S. (2000). Handbook of qualitative Research ( ${ }^{\text {nd }}$ Ed.). Thousand Oaks, Sage publications, Inc.

Dewey, J. (1902). The Child and the Curriculum. Chicago, University of Chicago Press.

Diaw, C. (2008). Quality and gender equality in education: What have we learned from FAWE's 15 years of experience? In M. Tembon \& L. Fort (Eds.), Girls Education in the 21st Century: Gender Equality, Empowerment, and Economic Growth (pp.253-267). Washington, DC: World Bank.

FAWE (2000). Girls Education in Africa: The FAWE Response. Nairobi: Forum for African Women Educationalists.

FAWE (2001). Gender responsive school management systems. Nairobi: Forum for African Women Educationalists.

FAWE (2006b). Gender Responsive Pedagogy. Nairobi: Forum for African Women Educationalists.

Feagin, J., Orum, A., \& Sjoberg, G. (Eds.), (1991). A case for case study. Chapel Hill, NC: University of North Carolina Press.

Gentemann, K. M., \& Whitehead, T. L. (1983). The cultural broker concept in bicultural education. Journal of Negro Education, 52(2), 118-129.

Glesne, C., \& Peshkin, A. (1992). Becoming qualitative researchers: an introduction. White Plains, NY: Longman.

Kirk, J. (2008). Addressing gender disparities in education in contexts of crisis, postcrisis, and state fragility. In M. Tembon \& L. Fort (Eds.), Girls education in the 21st Century: Gender equality, empowerment, and economic growth (pp.153-177). Washington, DC: World Bank.

Kvale, S. (1996). Interviews: an introduction to qualitative research interviewing. Thousand Oaks, Calif., Sage Publications.

Leshoai, B. L. (1978). Drama as a means of education in Africa. (Unpublished doctoral dissertation). University of Dar es Salaam, Tanzania.

Lincoln, Y. S., \& Guba, E. G. (1985). Naturalistic inquiry. Beverly Hills, Sage Publications. Miles, M. B., \& Huberman, A. M. (1994). Qualitative Data Analysis: An Expanded Sourcebook. Thousand Oaks: Sage Publications.

AJOTE Vol. 2. No. 2 (2012) 


\section{Kennedy Ongaga and Mary Ombonga}

Mlama, P. (1983). Tanzanian traditional theatre as a pedagogical institution. (Unpublished doctoral dissertation). University of Dar es Salaam, Tanzania.

Mlama, P. (2005). Gender and education for rural people in Africa: Policy lessons, options and priorities. Addis Ababa, Ethiopia: Forum for African Women Educationalists.

Noddings, N. (2002a). Educating moral people: A caring alternative to character education. New York: Teachers College Press.

Ongaga, K., \& Ombonga, M. (2009). From ruined hopes to great expectations: Strategies for educating vulnerable girls in a Center of Excellence, Kenya. International Journal of Educational Policies, 3(1), 32-50.

Patton, M. Q. (2002). Qualitative Research and Evaluation Methods. Thousand Oaks, CA: Sage Publications.

Rihani, M. A. (2006). Keeping the promise: Five benefits of girls' secondary education. Washington, DC: Academy for Educational Development.

Shor, I. (1992). Empowering education: Critical teaching for social change. Chicago: University of Chicago Press.

Stake, R. E. (1995). The Art of case study research. Thousand Oaks: Sage.

Tembon, M., \& Fort, L. (2008). Girls Education in the 21st Century: Gender Equality, Empowerment and Growth. Washington DC: World Bank.

Thompson, C., \& Ongaga, K. (2011). Flying the Plane While We Build It. A Case Study of an Early College High School. The High School Journal. 94, pp. 43-57. DOI:

10.1353/hsj.2011.0000.

UNICEF (2003). The state of the world's children report: Girls education and development. New York: UNICEF.

UNICEF (2009). Child friendly schools manual. Unite for Children. New York. Retrieved from http://www.ungei.org/resources/1612_2139.html

Winegardner, K. E. (1999). The case study method of scholarly research. The Graduate School of America. Retrieved from: http://www.tgsa.edu/online/cybrary/case1.html.

AJOTE Vol. 2. No. 2 (2012) 